\title{
REAÇÕES TRANSFUSIONAIS: DIAGNÓSTICO E TRATAMENTO
}

\author{
TRANSFUSION REACTIONS: DIAGNOSIS AND TREATMENT
}

Luciana C. O. Oliveira ${ }^{1} \&$ Ana Paula C. N .C. Cozac ${ }^{2}$

\begin{abstract}
${ }^{1}$ Médica Assistente. Disciplina de Hematologia. Hospital das Clínicas da Faculdade de Medicina de Ribeirão Preto - USP. ${ }^{2}$ Médica Assistente. Fundação Hemocentro de Ribeirão Preto

CorResPondênCIA: Luciana Correa Oliveira de Oliveira. Laboratório de Hematologia. Hospital das Clínicas de Ribeirão Preto. Campus Universitário. CEP 14.048-900 Ribeirão Preto - SP. Fone: (16) 602-2294. E-mail: lucoliveira@hotmail.com
\end{abstract}

OLIVEIRA LCO \& COZAC APCNC. Reações transfusionai: Diagnóstico e tratamento. Medicina, Ribeirão Preto, 36: 431-438, abr./dez. 2003.

RESUMO - A maior parte das transfusões resulta em reposição temporária, efetiva e segura de hemocomponentes. Como outras intervenções médicas, entretanto, as transfusões são associadas a certos riscos, e, somente quando os benefícios esperados sobrepõem os riscos potenciais, a transfusão deve ser iniciada. Este capítulo discorre sobre as principais categorias de reações transfusionais, discutindo a fisiopatologia, o diagnóstico, o tratamento, e a prevenção dessas reações.

UNITERMOS - Reações Transfusionais.

\section{1- INTRODUÇÃO}

Pacientes com perda aguda de sangue ou anemia sintomática, freqüentemente, requerem transfusão de hemocomponentes. E, embora a transfusão seja uma forma de terapia segura e efetiva, existe o risco de efeitos adversos. É necessário, portanto, que os médicos emergencialistas conheçam os princípios da prática transfusional e sejam capazes de manejar as reações transfusionais adversas, que variam desde febre autolimitada até hemólise intravascular, grave.

As reações transfusionais podem ser classificadas em agudas ou tardias, imunológicas e não imunológicas. (Tabelas I e II).

As principais reações são comentadas a seguir.

\section{2- TIPOS DE REAÇÃO}

\section{1- Reação Hemolítica Aguda}

Reação hemolítica, aguda é conseqüente à trans- fusão de concentrado de hemácias $\mathrm{ABO}$, incompatível, na maioria dos casos. É temida na prática transfusional devido a sua gravidade e alto índice de mortalidade. Ocorre, principalmente, devido a erros de identificação de amostras de pacientes e apresenta uma incidência de 1 caso para 33.000, em 12.000 transfusões. Os anticorpos de ocorrência natural anti-A, Anti-B e Anti-A,B do paciente reagirão com as hemácias $\mathrm{A}, \mathrm{B}$ ou $\mathrm{AB}$ do doador, causando hemólise intravascular das hemácias transfundidas, e por mecanismo de bystandard, de parte das hemácias do próprio paciente. O quadro é composto por dor no tórax, no local de infusão, abdome e/ou flancos, hipotensão grave, febre e hemoglobinúria. Pode evoluir para insuficiência renal aguda (IRA) devido a 3 fatores: vasoconstricção por liberação de catecolaminas, hipotensão sistêmica e formação de trombos intravasculares. A coagulação intravascular, disseminada (CIVD) é uma complicação comum devido à circulação de estroma celular (hemólise), promovendo a 
Tabela-I - Reações Transfusionais, Agudas

Tipos de Reação

Causa Principal

\section{Imunológicas}

Hemolítica

Incompatibilidade $\mathrm{ABO}$

Anafilática

Anticorpo do paciente contra IgA do plasma do doador

Febril não hemolítica

Anticorpo do paciente contra antígenos leucocitários do doador

Urticariforme

Anticorpo do paciente contra proteínas plasmáticas do doador

TRALI

Anticorpos do doador contra leucócitos do paciente

\section{Não imunológicas}

Sobrecarga de volume

Volume excessivo em pacientes com ICC

Contaminação bacteriana

Contaminação do hemocomponente por bactérias

Embolia gasosa

Infusão endovenosa de ar

Hipotermia

Infusão rápida de hemocomponente frio

Hipercalemia

Infusão rápida de várias unidades de sangue estocado

Hipocalcemia

Transfusão maciça de sangue citratado

Tabela-II - Reações Transfusionais, Tardias

Tipos de Reação

\section{Causa Principal}

\section{Imunológicas}

Hemolítica tardia

Resposta amnéstica ao antígeno eritrocitário, transfundido

DEVH-PT

Linfócitos funcionais no hemocomponente transfundido

Púrpura pós-transfusional

Desenvolvimento de anticorpo antiplaquetário

(anti-HPA- 1a )

\section{Não imunológicas}

Sobrecarga de ferro

Múltiplas transfusões

Hepatites (principalmente B e C)

Infecção por HIV

Infecção por Citomegalovírus

Malária

Doenças infecciosas

Infecção pelo HTLV I/II

Brucelose

Babesiose

Doença de Chagas

Parvovirose

Sífilis 
ativação do Fator XII da coagulação. É importante ressaltar que as manifestações da CIVD podem ser o único indício de reação hemolítica, aguda, nos pacientes anestesiados.

Sempre que houver suspeita de reação hemolítica, aguda, a transfusão deverá ser imediatamente suspensa, realizada a checagem da identificação da bolsa e do paciente (nome do paciente, registro, $\mathrm{ABO}$ do paciente, identificação da bolsa, ABO da bolsa) para evidenciar provável troca de amostra/paciente. Outra via de acesso deve estar disponível para iniciar hidratação.

O diagnóstico, além de clínico, baseia-se nos achados laboratoriais como, Coombs Direto positivo (realizado no banco de sangue), hemoglobinemia, queda da hemoglobina/hematócrito e, após algumas horas, elevação dos níveis de bilirrubina indireta.

$\mathrm{O}$ tratamento consiste em manter uma diurese de $100 \mathrm{ml} / \mathrm{h}$ por pelo menos $18-24 \mathrm{~h}$ através da infusão de soro fisiológico. O uso concomitante de diuréticos deve ser avaliado (furosemida $40-80 \mathrm{mg}$ uma a duas doses) com o objetivo de estimular a diurese e aumentar o fluxo renal. A suspeita de necrose tubular, aguda (NTA) deve ser cogitada, caso isto não ocorra. A hipotensão deve ser abordada com o uso de dopamina em baixas doses $(<5 \mu \mathrm{g} / \mathrm{Kg} / \mathrm{min})$, com o objetivo de aumentar o débito cardíaco e dilatar a vasculatura renal. O uso de heparina é questionável, já que a coagulopatia estabelecida é autolimitada. Plasma fresco, congelado (PFC $10 \mathrm{ml} / \mathrm{Kg}$ de peso) e crioprecipitado (se fibrinogênio $<100 \mathrm{mg} / \mathrm{dl}$ ) deverão ser usados em casos de sangramento de risco. A transfusão de concentrado de hemácias pode ser realizada, caso seja necessário.

A prevenção da reação hemolítica aguda consiste no cuidado da rotina em todas as etapas relacionadas à transfusão, desde a identificação correta da amostra pré-transfusional até a conferência da identificação da bolsa e do paciente, no momento da instalação do hemocomponente.

\section{2- Reações Anafiláticas}

A incidência desse tipo de reação é pequena. Ocorre em aproximadamente 1 a cada 170.000, em 18.000 transfusões. Pode começar após infusão de poucos mililitros do componente, com sintomas sistêmicos discretos no início, podendo progredir com perda de consciência, choque, e, em casos raros, morte. Os sintomas iniciais, geralmente, são náuseas, vômi- tos, cólicas abdominais e diarréia. Hipertensão transitória é seguida de profunda hipotensão. Rubor generalizado e, ocasionalmente, calafrios, podem estar presentes, mas febre não é um sinal encontrado. O rápido início de sintomas gastrointestinais e choque, na ausência de febre, freqüentemente, distingue esse tipo de reação de reações hemolíticas, sépticas e ou incompatibilidade leucocitária.

A explicação clássica para esse tipo de reação é a presença de anticorpos anti- $\operatorname{IgA}$ em receptores congenitamente deficientes dessa classe de imunoglobulina. Esses anticorpos IgA específicos reagem com as proteínas IgA do soro do componente transfundido. Outras classes de imunoglobulinas podem estar implicadas nesse tipo de reação. Anafilaxia a outros constituintes do produto, tais como anticorpos preexistentes contra outras proteínas séricas, anafilatoxinas derivadas de complemento, drogas ou outros alérgenos solúveis, presentes no componente transfundido podem também resultar em anafilaxia. Histamina préformada, serotonina e fator de ativação plaquetária em plaquetas estocadas podem ser capazes de produzir broncoespasmo, hipotensão, ou ambos, mimetizando uma reação de hipersensibilidade imediata. A determinação de $\operatorname{IgA}$ do paciente, quando possível, faz o diagnóstico da reação decorrente de anti-IgA. Se o nível de IgA for normal, outras causas estão envolvidas na gênese da reação.

$\mathrm{O}$ tratamento se inicia com a parada imediata da transfusão. Epinefrina aquosa 1:1000 deve ser administrada na dose de $0,2-0,5 \mathrm{ml}(0,2-0,5 \mathrm{mg})$, em injeção subcutânea ou intramuscular. Injeções podem ser repetidas a cada 15-30 min. Infundir grande quantidade de fluído endovenoso ( salina, soluções colóides, expansores plasmáticos) para repor a perda do intravascular para os tecidos. Outras drogas vasopressoras (dopamina em altas doses, norepinefrina) podem ser necessárias, se o paciente permanecer hipotenso, a despeito da epinefrina. Obstrução das vias aéreas pode ser causada por edema de laringe e hipofaringe ou broncoespasmo. É necessário fazer manutenção da permeabilidade e oxigenação, podendo ser necessária a intubação orotraqueal ou a traqueostomia. Broncoespasmo responde a epinefrina subcutânea ou terbutalina. A inalação de $\beta 2$-adrenergicos e a administração endovenosa de teofilina são efetivas para o broncoespasmo. O uso de anti-histamínicos (anti H1 e $\mathrm{H} 2$ ) pode ser útil como terapia adjuvante para o alívio de manifestações de urticária, angioedema, prurido e 
cólicas gastrointestinais. Corticóides não são úteis para a reversão da obstrução respiratória ou choque. Sob hipótese nenhuma a transfusão deve ser reinstalada.

Faz-se a prevenção com o uso de concentrado de hemácias lavadas ou, se disponível, de hemocomponentes de doadores deficientes de IgA.

\section{3- Reação Febril Não Hemolítica}

É caracterizada pelo aumento de mais de $1{ }^{\circ} \mathrm{C}$ da temperatura corporal, associada à transfusão de hemocomponentes, na ausência de causa subjacente. Geralmente, é acompanhada de tremor, que pode ser intenso e, em alguns casos, apresentar-se como única manifestação. Ocorre em $0,5-1,5 \%$ das transfusões, preferencialmente em pacientes politransfundidos. $\mathrm{Na}$ grande maioria dos casos, tem evolução benigna e pode ocorrer no início, durante ou horas após o término da infusão do hemocomponente. Ocorre por 2 mecanismos distintos. $O$ primeiro por interação entre anticorpo no plasma do receptor (paciente) e antígeno leucocitário ou plaquetário, presente no hemocomponente transfundido, e o segundo, pela liberação de citocinas acumuladas na bolsa durante sua estocagem.

Sempre que houver suspeita de reação febril não hemolítica, a transfusão deverá ser descontinuada, o paciente medicado com Paracetamol $750 \mathrm{mg}$ e Meperidina, este último, caso o tremor seja intenso. O diagnóstico desse tipo de reação é clínico e de exclusão.

Medidas profiláticas podem ser tomadas após o segundo episódio leve ou após o primeiro, desde que este tenha sido grave, utilizando-se Paracetamol 1hora antes da transfusão. Caso a medicação não evite a ocorrência de reações futuras, pode-se optar pela filtragem do concentrado de hemácias e dos concentrados de plaquetas.

\section{4- Reação Urticariforme}

Ocorre em 1 - 3\% das transfusões. É resultante da reação antígeno-anticorpo, sendo os antígenos representados por substâncias solúveis no plasma da unidade doadora contra os quais o receptor tenha sido sensibilizado previamente. O quadro clínico é caracterizado por pápulas pruriginosas e/ou vermelhidão da pele. Geralmente, apresenta boa evolução.

A transfusão deve ser interrompida, o paciente medicado com anti-histamínico (Desclorferinamina 5 mg preferencialmente via parenteral - EV). Se a reação for branda, o hemocomponente pode ser reinstalado. O diagnóstico é clínico. A prevenção pode ser feita após o terceiro episódio leve ou após o primeiro, desde que este tenha sido grave, utilizando antihistamínico $1 \mathrm{~h}$ antes da transfusão. Caso a medicação não evite a ocorrência de reações futuras, podese optar pela lavagem do concentrado de hemácias. No caso de concentrado de plaquetas, tal procedimento somente estará indicado se a reação for grave, já que a lavagem reduz consideravelmente sua eficácia transfusional.

\section{5- TRALI (Transfusion-Related Acute Lung Injury)}

É de incidência desconhecida. Deve-se suspeitar de TRALI, em pacientes que estejam recebendo transfusão ou foram recentemente transfundidos ( em geral, até $6 \mathrm{~h}$ após o término) e apresentem insuficiência respiratória aguda e imagem em raio $\mathrm{X}$ que sugere edema pulmonar, sem evidências de falência cardíaca. A gravidade do quadro respiratório é, geralmente, desproporcional ao volume de sangue infundido, que em geral, é muito pequeno para produzir hipervolemia. Em contraste com a sobrecarga de volume, os pacientes com TRALI possuem pressão venosa central, normal e pressão capilar, pulmonar, normal ou baixa. A reação pode incluir calafrios, febre, cianose e hipotensão. TRALI pode resultar de múltiplos mecanismos. Anticorpos contra HLA e antígenos do neutrófilo, transfundidos, podem reagir com os leucócitos do paciente, causando uma seqüência de eventos que aumentam a permeabilidade da microcirculação pulmonar, permitindo o extravasamento de líquidos para o espaço alveolar. Raramente, anticorpos, na circulação do receptor, podem reagir com granulócitos transfundidos, originando quadro semelhante. Outros mecanismos podem estar implicados na etiologia da TRALI, como ativação do complemento e geração de C3a e C5a, agregação dos granulócitos, gerando êmbolos na microvasculatura pulmonar, transfusão de citocinas que se acumulam em hemocomponentes estocados.

Se houver suspeita de qualquer tipo de reação pulmonar, aguda, a transfusão deve ser interrompida imediatamente. O tratamento desse tipo de reação baseia-se em reversão da hipoxemia com oxigenioterapia e ventilação mecânica, se necessário. A maioria dos pacientes recuperam a função pulmonar em 48 a 96 h. Na prevenção de novos episódios, nenhuma precaução especial se faz necessária, já que a causa é doador-específica e hemocomponentes de outros doadores são disponíveis. 


\section{6- Sobrecarga De Volume}

A transfusão pode causar edema agudo, de pulmão devido à sobrecarga de volume, em pacientes com reserva cardíaca diminuída. Adultos acima de 60 anos e crianças são especialmente susceptíveis. A incidência dessa reação é desconhecida, em grande parte, devido à subnotificação desse tipo de reação para o banco de sangue.

A transfusão deve ser interrompida e o paciente deve ser colocado em posição sentada. Diuréticos de ação rápida, como furosemida, devem ser utilizados via endovenosa. Manter aporte adequado de oxigênio, com máscara ou ventilação mecânica, se necessário. No caso de edema agudo de pulmão, medidas específicas adequadas devem ser tomadas (uso de nitratos, morfina, etc).

Como prevenção, em pacientes susceptíveis, a transfusão deve ser realizada lentamente ( por ex. 1 $\mathrm{ml} / \mathrm{Kg} / \mathrm{h}$ ). A administração de diuréticos pré e durante a transfusão podem ser úteis.

\section{7- Contaminação Bacteriana}

A contaminação bacteriana do hemocomponente pode ser responsável por bacteremia aguda. A taxa de reações adversas, decorrentes de contaminação, é estimada em 1 para cada 1700 unidades de plaquetas e 1 a cada 500000 unidades de hemácias.

As reações se caracterizam por febre $\left(\geq 39^{\circ} \mathrm{C}\right.$ ou aumento de $2^{\circ} \mathrm{C}$ em relação à temperatura prétransfusional), calafrios intensos, tremores, taquicardia ( $\geq 120 / \mathrm{min}$ ou aumento de $40 / \mathrm{min}$ ), aumento ou queda de $30 \mathrm{mmHg}$ na pressão arterial sistólica. Outros sintomas podem estar associados como náuseas, vômitos, dor lombar e respiração encurtada. Assim que a possibilidade desse tipo de reação seja considerada, a transfusão deve ser interrompida. O hemocomponente e o equipo utilizado para transfusão devem ser encaminhados para o banco de sangue. Amostra de sangue do paciente e a do hemocomponente em questão devem ser enviadas para cultura com pesquisa para bactérias aeróbias e anaeróbias. Mudança da coloração do conteúdo da bolsa para púrpura escura, presença de grumos em seu interior e hemólise sugerem contaminação bacteriana. Como inicialmente o quadro clínico é muito semelhante ao da reação hemolítica aguda, deve-se proceder investigação a fim de descartá-la (conforme já descrito anteriormente).

O tratamento desse tipo de reação consiste na utilização de antibióticos de largo espectro, combina- dos com terapia para choque séptico, falência renal e CIVD, que podem acompanhar o quadro. A antibioticoterapia deve ser reavaliada após o resultado da cultura.

\section{8- Reação Hemolítica Tardia}

Ocorre em $0,05-0,07 \%$ das transfusões. A reação hemolítica tardia é extravascular e ocorre devido à produção de anticorpos antieritrocitários (outros antígenos de grupo sangüíneo que não $\mathrm{ABO}$ ) após transfusão ou gestação prévias, onde haja exposição do paciente a antígenos que ele não possua, por exemplo, paciente Kell negativo recebe uma transfusão de concentrado de hemácias Kell positivo. A reação pode ocorrer horas a semanas (até 3 semanas) após a segunda exposição ao antígeno em questão.

O quadro clínico é composto de febre, icterícia e queda da hemoglobina ou aproveitamento transfusional, inadequado. Tal tipo de reação deverá ser suspeitado sempre que ocorrer aproveitamento inadequado da transfusão ou febre sem causa aparente, mesmo na ausência de icterícia.

O diagnóstico é feito após enviar ao laboratório de imunoematologia (no Campus e Unidade de Emergência, localiza-se no banco de sangue) 2 amostras do paciente, uma sem e outra com anticoagulante, para que sejam realizados pesquisa de anticorpos irregulares (PAI) e Coombs Direto (CD), respectivamente. A presença de um novo anticorpo, seja no soro (PAI+) ou ligado às hemácias $(\mathrm{CD}+)$ do paciente, fecham o diagnóstico.

O tratamento é desnecessário. Se houver necessidade de transfusões futuras, o concentrado de hemácias deverá ser antígeno negativo para o correspondente anticorpo identificado com o objetivo de evitar reações.

\section{9- Púrpura Pós-Transfusional}

A púrpura pós-transfusional ocorre raramente (200 casos relatados até o momento), sendo caracterizada por queda repentina do número de plaquetas, geralmente abaixo de $10.000 / \mathrm{mm}^{3}, 05$ a 10 dias após a transfusão em pacientes com história prévia de gestação ou transfusão. O quadro é, geralmente, autolimitado, com resolução em cerca de 3 semanas. Dez a quinze por cento dos pacientes evoluem para óbito, por sangramento no SNC. A destruição das plaquetas ocorre por produção de anticorpos contra o antígeno plaquetário HPA-1a (presente em 98\% dos indivíduos), ocorrendo destruição das plaquetas transfundidas e 
do próprio paciente, apesar de o mesmo ser antígeno negativo (HPA-1a negativo). Os mecanismos implicados na destruição das plaquetas do próprio indivíduo ainda não estão claros, porém, acredita-se que se deva por adsorção plaquetária de antígenos solúveis no plasma, destruição mediada por complexo antígenoanticorpo, reação cruzada do anticorpo ou por produção de auto-anticorpos. O uso de corticóide ainda é controverso. Os tratamentos de escolha são imunoglobulina intravenosa (IGIV), em altas doses, ou plasmaférese, sendo o último menos efetivo. A transfusão de plaquetas pode ser realizada, se o concentrado for HPA-1a negativo, utilizando-se IGIV concomitantemente. Como concentrados HPA-1a negativos não são normalmente disponíveis, a transfusão de plaquetas fica contra-indicada.

\subsection{0- Doença Do Enxerto Versus Hospedeiro Pós-Transfusional (DEVH-PT)}

A DEVH-PT é extremamente rara, ocorre quando linfócitos viáveis, contidos no hemocomponente transfundido não são eliminados pelo sistema imunológico do paciente, sendo eles capazes de reconhecem como estranhos, tecidos e órgãos do receptor, através de diferenças antigênicas de HLA. Os fatores de risco, associados à DEVH-PT são a presença de linfócitos viáveis no hemocomponente, no caso de pacientes imunocomprometidos e a semelhança entre HLA do doador e receptor, em indivíduos imunocompetentes. O quadro é caracterizado por pancitopenia refratária, febre, dermatite, alteração de função hepática (elevação de transaminases e bilirrubinas), enterocolite com diarréia aquosa de 3-4 1 por dia, náuseas e vômitos que têm início 04 a 30 dias após a transfusão. A DEVH-PT pode ocorrer em pacientes suscetíveis, que recebam transfusão de qualquer hemocomponente que contenha linfócitos viáveis. O tratamento, geralmente, é ineficaz, ocorrendo óbito em mais de $90 \%$ dos pacientes. A profilaxia deve ser feita, irradiandose os hemocomponentes celulares (sangue total, concentrado de hemácias, concentrado de plaquetas e granulócitos) com dose de 2.500 cGy. A prescrição de hemocomponentes irradiados deverá ser restrita às seguintes situações: 1- recém-nascidos prematuros; 2exsangüíneotransfusão e transfusão intra-uterina; 3pacientes oncoematológicos em quimioterapia; 4- pacientes portadores de neuroblastoma em quimioterapia; 5- portadores de imunodeficiências congênitas; 6doadores relacionados (pai/mãe/irmão); 7- portadores de Anemia Aplástica; 7- transplantes.

\subsection{1- Sobrecarga De Ferro}

Ocorre em pacientes cronicamente transfundidos, especialmente os portadores de hemoglobinopatias dependentes de transfusão. Esses pacientes apresentam um acúmulo progressivo de ferro, excedendo a capacidade fisiológica de excretá-lo. A estocagem desse elemento se dá, inicialmente, no retículo endotelial e, após saturados esses sítios, há o depósito nas células parenquimais, interferindo com a função de órgãos, como coração, fígado, glândulas endócrinas. A falência hepática e a toxicidade cardíaca são as complicações mais graves. Essas complicações, geralmente, ocorrem em pacientes que foram expostos a mais de 50-100 unidades de concentrado de hemácias, na ausência de sangramento.

$\mathrm{O}$ tratamento visa à retirada de ferro, sem a redução da hemoglobina do paciente. Para esse fim, são usados agentes de quelação do ferro, de uso subcutâneo ou endovenoso, como a desferoxamina e, mais recentemente, a deferiprona, que é de administração oral.

\subsection{2- Complicações Infecciosas}

Durante as últimas décadas, as taxas desse tipo de complicação diminuíram drasticamente, devido à extensa pesquisa para caracterizar os patógenos transmitidos por transfusão, caracterização da dinâmica das infecções, implementação de critérios mais rígidos na seleção de doadores e aumento da sensibilidade dos métodos laboratoriais para screening. Os principais patógenos envolvidos são os vírus das Hepatites B e C, HIV 1 e 2, HTLV I e II (sendo só tipo I associado a desenvolvimento de doença clínica), Citomegalovírus, Parvovírus, os parasitas relacionados a Doença de Chagas, Málaria, Babesiose e Sífilis. Nos EUA, as incidências de contaminação por HIV, Hepatite B e Hepatite C são respectivamente 1:676.000, 1:63.000, 1:103.000 transfusões. Na cidade de Ribeirão Preto, a incidência de contaminação por HIV é de 1 a cada 300.000 transfusões. Essa taxas variam com a população estudada e com os exames realizados para detecção dos agentes infecciosos.

TODAS AS SUSPEITAS DE REAÇÃO TRANSFUSIONAL DEVEM SER NOTIFICADAS (Ficha de Notificação de Reação Transfusional)!

O quadro clínico e tratamento das reações transfusionais estão sumarizadas na Figura 1. 
Sinais/sintomas de reação transfusional aguda Febre/ calafrios/ taquicardia/ hiper ou hipotensão, choque, rubor, urticária, dores abdominal, torácica, muscular, dispnéia, náusea

Parar a transfusão e contactar o médico responsável Medir a temperatura, pulso, FC, FR, checar saturação de $\mathrm{O}_{2}$. Checar a identificação do paciente e da bolsa.

Reação febril não-hemolítica

Aumento $<1,5^{\circ} \mathrm{C}$ na temperatura, paciente estável e bem. Administrar Paracetamol VO

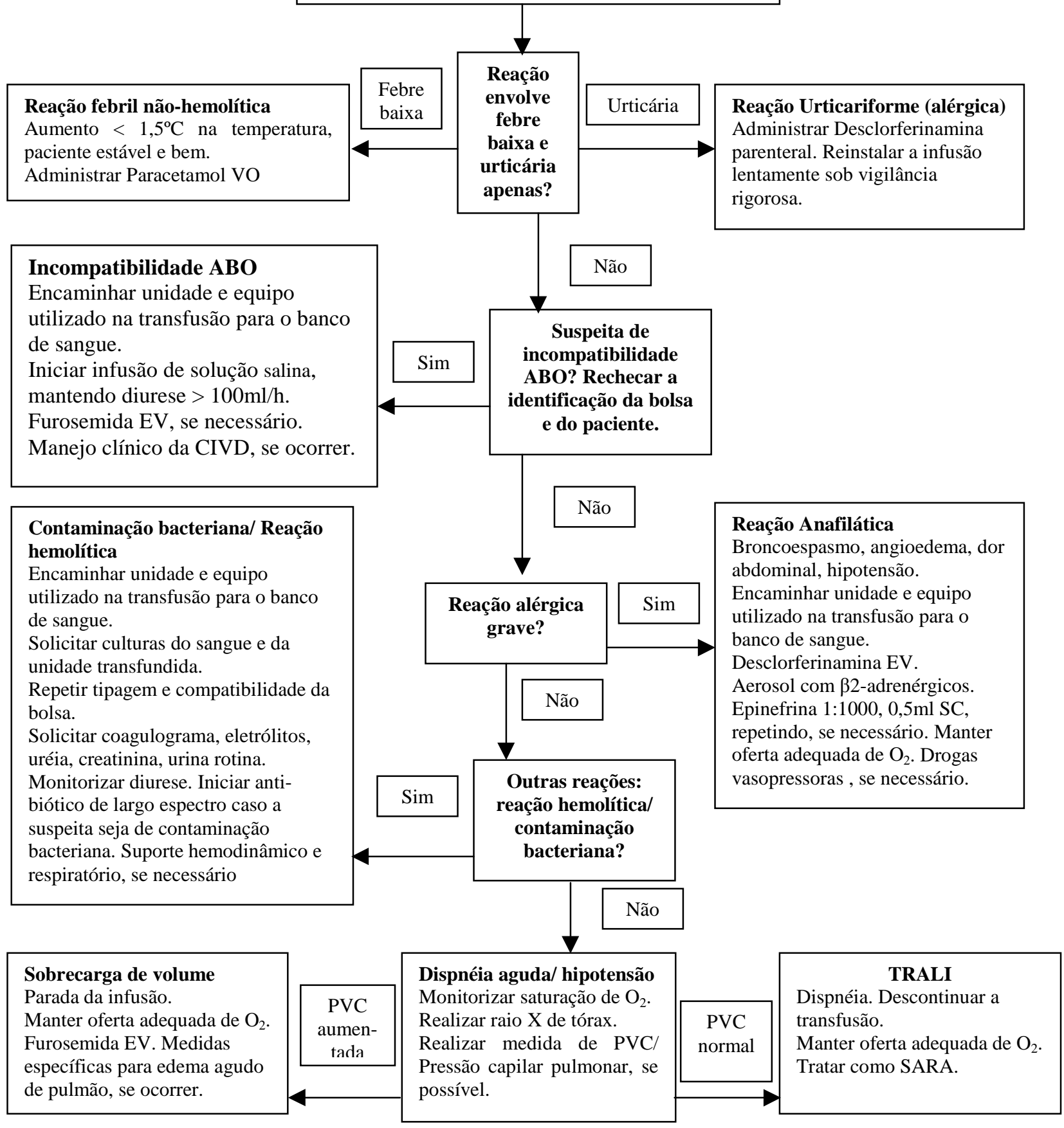

Figura 1- Manejo das reações transfusionais agudas 
OLIVEIRA LCO \& COZAC APCNC. Transfusion reactions: Diagnosis and treatment. Medicina, Ribeirão

Preto, 36: 431-438, apr./dec. 2003

ABSTRACT - Most transfusion provide safe and effective temporary replacement of blood components. As with other medical interventions, however, transfusions are associated with certain risks, and only when the expected benefits outweigh the potential risks should transfusion therapy be initiated. This chapter addresses the principal categories of transfusion reactions. For each individual type of reaction, the pathophysiology, diagnosis, treatment, and prevention are discussed. More detailed coverage is available elsewhere.

UNITERMS - Transfusion Reactions.

\section{BIBLIOGRAFIA RECOMENDADA}

1 - AMERICAN ASSOCIATION OF BLOOD BANKS. Technical manual, 13th ed, AABB, Bethesda, chap. 27: 577-600, 1999.

2 - AMERICAN ASSOCIATION OF BLOOD BANKS. Technical manual, 13th ed, AABB, Bethesda, chap. 28: 601-634, 1999.

3 - JENNER PW \& HOLLAND PV. Diagnosis and management of transfusion reactions. In: PETZ LA; KLEINMAN S; SWISHER SN; SPENCE RK \& STRAUSS RG, eds. Clinical practice of transfusion medicine, 3rd ed, Churchill Livingstone, New York, p. 905-929, 1996.
4 - POPOVSKY MA. Transfusion and lung injury. Transfus Clin Biol 8: 272-277, 2001.

5 - KISHIYAMA JL \& ADELMAN DC. Allergic and immunologic disorders. In: TIERNEY LA; MCPHEE SJ \& PAPADAKIS MA, eds. Current medical diagnosis and treatment, 41st ed, McGraw-Hill, New York, p. 807-831, 2002.

6 - WILLIANSON ML. Systems contribuiting to the assurance of transfusions safety in the United Kingdom, Vox Sanguinis 77: 82-87, 1999 